\title{
Individualised Professional Development in Higher Education
}

\author{
Betty McDonald
}

\begin{abstract}
Whenever we think about professional development (PD) we often think about groups, and rarely about individuals, despite the fact that groups are made up of individuals. What we experience in a group is not only the sum of the idiosyncrasies of the individuals in the group, but a host of intermingling factors that come into play whenever a group meets. The research question was: How did instructors in Higher Education experience individualised professional development? Instructors were defined as those individuals teaching courses at the university. By regulation, they are required to have minimal qualifications, at least one level above the level at which they are currently teaching. The paper shares some of the lived experiences that instructors at a university had with Individualised Professional Development (IPD). The sample comprised 12 (8 females) instructors from a university that engaged in IPD, using the services of this researcher's HelpDesk. Subjects ranged from 25 to over 60 years old and were actively engaged in teaching at the researcher's university. The length of time for individual visits to the HelpDesk ranged from 30 minutes to two hours, depending on the instructor's self perceived needs. The study assumes that instructors were open and honest in their responses about IPD; committed to personal development; and put into practice skills learned. The small sample size, selected from one HE institution limited generalisability. Possible Hawthorne's or Henry's Effect may have been in action and the interplay of several possible factors was not considered. Practical, tried-and-tested methods used included case studies; consultations; coaching; communities of practice; lesson studies; mentoring; reflective supervision; and technical assistance. This researcher conducted numerous semi-structured interviews (protocols available upon request from the author) with several instructors in HE in order to obtain useful, detailed information about their reactions to IPD method/s used. Instructors shared their personal lived experiences that give us some insights into what other researchers and practitioners may find useful in their ongoing IPD practice.
\end{abstract}

Keywords-andragogy, experience, faculty, individualised professional development.

\section{INTRODUCTION}

$\mathrm{I}_{\mathrm{i}}$ MAGINE life without continuous improvement! Imagine an institution where there is no form of professional development! How can we maintain quality and ensure effectiveness in programme delivery? How can we keep faculty updated with the latest pedagogy and technology? If left alone limited faculty members may choose to self improve because of

Professor Betty McDonald, Author is with the University of Trinidad and Tobago, Republic of Trinidad and Tobago, Caribbean (e-mail: betty.mcdonald@utt.edu.tt).

Professor Betty McDonald thanks the Commonwealth Scholarship Commission (CSC) in the UK under The Association of Commonwealth Universities (ACU), Grant TTCP-2016-95, at The University of Bristol, BS8 $1 \mathrm{JA}, \mathrm{UK}$. intrinsic motivation, or otherwise. Clearly, there is need for continually developing and improving the skills of employees so they could address societal issues and respond to their civic responsibilities. Additionally, there is need to satisfy the employees' desire to self actualise, in keeping with Maslow's well recognised and accepted hierarchy of needs.

The point has to be made clear that this paper is not intended to promote Individualised Professional Development (IPD) over group professional development because each approach has its place in the scheme of things. It is not a one size-fits-all situation. While IPD may be useful at some times, under certain circumstances, group professional development may be more appropriate and vice versa. The bottom line is that the individual experiences, personal growth and self actualisation manifest themselves in not only organisational improvement, but improved learning, behaviors and attitudes, license renewals and district accreditations, to mention a few. In a sense, IPD is an investment in lifelong learning as individuals are provided with time, resources and opportunities to reflect on and assess their own teaching methods; work together as professionals, developing and implementing institutional improvement plans, and staying abreast of current research in their respective fields of study.

\section{BACKGROUND}

\section{Higher education (HE)}

By HE, oftentimes referred to as tertiary education, we mean a 'final' stage of formal learning that takes place post secondary institution. Generally, individuals voluntarily opt to participate in HE to achieve a personal goal like enhanced social mobility; better job opportunities; improved living conditions; more autonomy; or self actualisation. While it is appreciated that learning is lifelong, that is, learning takes place from the 'womb to the tomb', HE formalises the process as distinct from everyday learning that naturally occurs throughout life. Accordingly, HE is often delivered by tertiary educational institutions like colleges, universities, vocational schools, technology schools, career centres, etc. Terms like further education or continuing education are popular among certain groups. Formal teaching, research, innovations, etc. are frequently the methods of engagement utilised in HE. Credentials for HE may include diplomas, degrees, or recognition with an honorary title for notable contributions made to society. Accordingly, the issues of IPD in HE seemed worth investigation.

This paper draws information from the lived experiences of a sample of instructors engaged in ongoing IPD at the only national university in the country. Instructors were defined as those individuals teaching courses at the university. By 
regulation, they are required to have minimal qualifications, at least one level above the level at which they are currently teaching. Instructors at the university work across programmes rather than departments, thereby encouraging an interdisciplinary flavor to training of students operating from 16 teaching and research campuses, scattered throughout two island states. Programmes are intended to serve the ongoing developmental needs of the country. Animation Studies; Agriculture; Aviation; Environmental Studies; Engineering; Education; Entrepreneurship \& Commercial Studies; Fashion \& Design; Information Communication Technology; Criminology \& Public Safety; Cultural Studies; Health Administration; Maritime Studies; Performing Arts; Sports \& Leisure Studies; etc. are some of the signature programmes offered face-to-face and in the blended format at different levels: certificates, diplomas, and degrees (undergraduate and postgraduate).

\section{LITERATURE REVIEW}

\section{Nature of Professional Development}

Professional Development (PD) encompasses ongoing learning opportunities available to employees to ensure they remain on 'top of their game', as they work together in a more effective and harmonious manner. These learning opportunities may be communities of practice, workshops, seminars, conferences, consultations, formal coursework, situated learning, coaching, mentoring, research work, reflective supervision, or various forms of informal learning and technical assistance. Skills and knowledge attained for both personal development and career advancement may be considered to be PD. Accordingly, ongoing learning, capacity building, up-skilling, work development or staff training may be often referred to as PD.

A growth-promoting learning process that empowers stakeholders (teachers, administrators, staff, and other school personnel) to improve the educational organisation is the manner in which The Mississippi Department of Education defined PD. In their eyes, the purpose of PD is to improve student learning by creating an environment that will enable stakeholders to invest in quality opportunities to grow individually and collaboratively; enhance job-related skills; acquire new knowledge; and share expertise and insights.

Wei et al. (2009) posited that the focus of effective professional development is to improve instructional practice by giving teachers new knowledge and techniques for assessing learning. The ultimate goal is to improve student learning. The Center for Technology in Learning, SRI International (2009) claimed that for professional development to lead to substantial teaching changes and improvements in student learning, it needs to (1) address all aspects of the teaching triangle and their interactions in context; (2) be implemented in a highly aligned manner; and (3) include time for teachers to collaborate during the change process. Cohen and Ball's (2000) teaching triangle depicts teaching as interactions among teachers, students and instructional materials.

It is normal that PD is intensive and collaborative. Wei et al (2009) believed that PD should be coherent and sustained; occur during the school day; be part of the teacher's professional responsibilities; and focus on student results.
Clearly, PD is a broad term incorporating a wide range of people, interests and approaches. Nevertheless, at the heart of $\mathrm{PD}$, is the enhancement of knowledge, skills and abilities for better job performance. Lifelong learning naturally tends to be a sequel of ongoing PD.

\section{Individualised Professional Development (IPD)}

Essentially, IPD is professional development administered on an individual or one-on-one basis, where the specific idiosyncratic individual needs of the recipient are addressed. IPD is particularly attractive to individuals because it provides them with learning opportunities that directly relate to their personal needs.

One of the hallmarks of IPD is constructivism. On their own, individuals have to make meaning of their lived experiences. Von Glasersfeld (1995, pp.15) is quoted to have said that 'constructivism does not claim to have made earth-shaking inventions in the area of education; it merely claims to provide a solid conceptual basis for some of the things that, until now, inspired teachers had to do without theoretical foundation'. In a sense, by constructing individualised meaning of experiences, learners now have a conceptual basis for operating in the manner in which they operate. Learning environments have to be developed to suit the individual learner. For instance, while it may be instructive to hold a discussion in an open space with one learner who has the capacity to focus on details under any conditions, it may not be helpful to do the same with another learner whose attention strays quickly.

Constructivism is often applied to the establishment of all learning environments and in particular to those in which IPD occurs. Jonassen (1994) held the view that teachers should create real-world, context-rich environments in which learning is relevant; focus on concrete approaches to solving real-world problems; serve as coaches and mentors as students solve these problems; stress conceptual interrelatedness; provide tools and environments that help learners interpret the multiple perspectives of the world; scaffold students as they seek to control and mediate their own learning.

In IPD, expert facilitators minimise reproduction and maximise knowledge construction. Rote learning is discouraged and deeper learning for understanding is encouraged. Accordingly, the natural complexity of the world needs to be recognised and be represented. In agreement with Jonassen (1994), instruction is not abstracted but rather, authentic tasks are utilised. Such tasks are based on real life situations or case studies that reflect such real life situations. It therefore would not be advisable to emphasise pre-determined instructional sequences that inhibit individual meaning making. Instead, enabling context and content-dependent knowledge construction seems the preferred way of operation. Jonassen advised that facilitators should support collaborative construction of knowledge through social negotiation.

According to the Mississippi Department of Education, the principles of excellence in PD that are applicable to IPD:

- are based on a shared vision and goals for improving student performance derived through a strategic planning process

- advance individual growth and organisational improvement

- involve institutional collaboration

- provide for networking and collegiality 
- model constructivist teaching that builds knowledge through exploring, debating, questioning, and reflecting

- provide time and follow-up necessary for change in practice

- are site-based and school-initiated

- have an evaluation component that focuses on improvement in teaching practice and in student results

- are ongoing and job-embedded

- enhance knowledge of subject matter, teaching and learning, and child development

- are supported by resources of time, money, and personnel

- address the diversity of all learners

- acknowledge the Standards for Staff Development published by the National Staff Development Council

- encourage individuals to generate, articulate, and disseminate knowledge based on their classroom experiences and action research

- allow stakeholders to develop and strengthen leadership skills.

With the exponential growth in technology, more and more institutions are turning to a hybrid or blended form of IPD. This significant paradigm shift to webinars, discussion boards, wikis, social networking, rich site summary (RSS), short message services (SMS), learning management systems, blogging, bulletin boards, Flickr, Wikipedia, Google searches, Google Docs and Microsoft 365 with all its new features make online IPD very attractive.

Interaction is facilitated and training can be optimised since participants need not travel long distances to get to their destinations. Rapid internet connectivity, together with light weight laptops, iPhones and iPads have facilitated interactivity and collaboration for IPD.

The common trend has been to augment traditional PD offerings with online resources, rather than totally replacing them. This has widened access not only to the quantity and quality of information, but also to the reachable audience. Reducing current expenditure has been a priority, especially in times of economic recession and uncertainty. Accountability and transparency have been important features in the process.

\section{Some Professional Development Models}

Several Professional Development Models inform this researcher's IPD since the specific programme was aimed at addressing the needs of the individual instructors. In a simplistic manner, there is reflection on current practice, asking questions like, 'What do I need to know?'; 'What do I need to be able to do?' The answers from these questions lead to planning ('How can I learn?'). This is followed by action or implementation, before proceeding to evaluation or reflection on learning. Questions like, 'What have I learned?' and 'How is it benefiting my practice?' arise from reflective activity in PD.

With special reference to IPD, we can refer to Alsop's continuing PD model that has a spiraling effect beginning with a vision of the individual's career path, followed by an identification of short and long term goals. For each PD activity, learning needs must be carefully defined and an action plan put in place. A performance review, and needs definition serve to provide data for a personal development plan. As progress is cross checked against the identified vision, ongoing IPD continues.
Finally, Christie's (2006) $\mathrm{E}^{6} \mathrm{PD}$ model is based on six principles; three of which guide curriculum and the other three that guide the learning process. Engagement, exchange of information, and empowerment are Christie's three curricular principles, while exploration, explanation, and exhibition are her three learning process principles. She posited that because teachers are learners, their PD must be personally and professionally relevant; allow for extensive information exchange; and must empower them to understand and use new technologies and strategies effectively in their classrooms.

\section{Professional Development Activities}

Professional development activities tend to include formal teacher induction; the credits or degrees teachers earn as part of recertification or to receive salary boosts; the national-board-certification process; and participation in subject-matter associations or informal networks (Sawchuk, 2010). PD activities may include multiple modes of learning like taking coaching and mentoring courses, internships, networks, partnerships, research, sabbaticals, seminars, study groups, teachers in residence, workshops and others. PD activities could also include both formal and informal types of training, available at any level within the academic hierarchy (post secondary, tertiary and beyond). The training may be pre service or in service. Such training may or may not lead to an official qualification but certainly some form of recognition that facilitates upward or lateral mobility is desired.

Professional development activities serve to prepare individuals to communicate using a variety of media and formats; access and exchange information in a variety of ways; compile, organise, analyse, and synthesise information; draw conclusions and make generalisations based on information gathered; know content and be able to locate additional information as needed; become self-directed learners; and collaborate and cooperate in team efforts.

Accordingly, as espoused by Honebein (1996), there is need for embedding experience within the knowledge-construction process; learning in realistic and relevant contexts; ownership and voice in the learning process; learning in social experience; the use of multiple modes of representation; and self-awareness in the knowledge-construction process.

IPD activities may last for varying periods. For example, they may last for several months, weeks, days or hours, held over a sustained period of block time or intermittently over a year. Training may be in leadership, management, critical thinking, soft skills, mediation, pedagogy, technology skills, among others. Both process and task skills are often intermingled.

\section{RESEARCH QUESTION}

The objective of this present paper was to examine the various ways IPD occurred in HE and hear what instructors in HE had to say about their personal lived experiences. Hence, the research question was: How did instructors in HE experience IPD?

\section{Methodology}

Participants for this study comprised 12 instructors (8 females) of various disciplines, voluntarily visiting the researcher's Professional Development HelpDesk for 
one-on-one assistance. They ranged from 25 to over 60 years old and were actively engaged in teaching at this researcher's university. The length of time for instructor visits to the HelpDesk ranged from 30 minutes to two hours, depending on the instructor's self perceived needs.

This researcher conducted numerous semi-structured interviews (protocols available upon request from the author) with the instructors in HE in order to obtain useful, detailed information about their reactions to IPD method/s they experienced.

\section{ASSUMPTIONS AND LIMITATIONS}

The study assumes that instructors were open and honest in their responses about IPD; committed to personal development; and put into practice skills learned. The small sample size, selected from one HE institution limited generalisability. Possible Hawthorne's or Henry's Effect may have been in action and the interplay of several possible factors was not considered.

\section{RESULTS}

Generally speaking, instructors were very articulate and knowledgeable about what they needed to address in their IPD experience. They presented their individual cases in a detailed professional manner and were very receptive to my advice. The females appeared to be more empathetic about their students' situations than their male counterparts who chose to express minimal or no emotions.

I used a variety of strategies based on the instructor's specific issues. Among the strategies used were a case study approach where instructors operated in the role of decision makers as they considered a given case or situation. The situations posed mimicked their self articulated situations. However, because they were asked to remove themselves from their situations and pretend that someone else had the specific issues, the instructors had the opportunity to make useful comments that actually helped them to address their own issues. For instance, Instructor A who was new to the university was assigned to Maritime Studies and needed to be brought up to speed before entering the classroom and be supported on an ongoing basis. I spent a lot of time with Instructor A differentiating the mode of operation of a seafarer from that of an academic, whose evaluation was judged under the categories of teaching, research and service. For example, in the area of teaching Instructor A would need to have her course outline; detailed lesson plans; instructional strategies; assessment procedures; documented evidence of contact hours with her students and feedback from them regarding their perception of their lived learning experiences. Invited lectures/seminars or presentations and other related teaching activities would form part of her teaching portfolio.

I also used a consultative approach designed to assist individual instructors to clarify and address immediate concerns by following a systematic problem-solving process. Because Instructor B had no internet access at home I encouraged her to purchase a smart phone or preferably an iPad so that she could use the university's Wifi facility open to faculty, staff and students. Instructor B was excited when she bought her iPad. She was able to access the internet and avail herself of a lot of current information. Instructor B found relevant conferences that allowed her to present her action research. She became really excited about her teaching and her students were aware of it. She wrote her reflections on her teaching, day after day and before long, she had enough information that allowed her to complete conference papers and journal manuscripts. On a one-on-one basis, I was able to edit materials for Instructor B and offer suggestions for improvement. I vividly remember how thrilled Instructor B was when her first conference abstract was accepted. She was literally overcome with joy and told just about everyone she met. Not only did her success encourage her to move on, but it also served as a form of powerful motivation for her colleagues and friends.

I used coaching to enhance Instructor C's competencies in a specific skill area by providing a process of observation, reflection, and action. Having only been exposed to traditional methods, Instructor $\mathrm{C}$ was interested in some of the many ways of assessment that he could use with his students. I suggested that he could use his students' online blogging for his course as an effective way of assessing student growth and development. In order to maintain a fair and transparent system, he needed to collaboratively design suitable rubrics that assigned marks for different levels of performance on a pre-determined domain and course content.

IPD for Instructor D underscored the role of communities of practice that seek to improve professional practice. Here Instructor D was able to engage in shared inquiry and learning with people who have a common goal.

For Instructor E, my IPD utilised lesson study which is aimed at solving practical dilemmas related to intervention or instruction through participation with other professionals in systematically examining practice. I encouraged Instructor E to get in touch with other instructors to formulate a Table of Specifications of Blue Print for her examinations. The Table of Specifications must address the cognitive, affective and psychometric or kinesthetic domains, agreed upon by the instructors constructing the test. Usually these domains are indicated in the learning outcomes specified in the course outline.

Mentoring or promoting Instructor F's awareness and refinement of PD by providing and recommending structured opportunities for reflection and observation proved very useful. As Instructor F progressed I thought it useful to expose him to aligned thinking which was meant to optimise his time. I asked Instructor F to write out exactly what he wanted in his professional life and also in his personal life. I advised him to review what he wrote regularly. Then I encouraged him to think of ways in which he could align his actions to what he valued most. I reminded him that what was past was already past and that he could do nothing about it. After much discussion, we agreed that the only thing over which Instructor $F$ was in control of was his actions right now (in the present). Instructor $F$ realised that he was much more empowered than he ever thought. He began asking himself, 'What do I control?'; 'How do I optimise it?'; 'How can I connect the dots of every action?'; 'How can I balance my personal and professional life?' 
Reflective supervision that supports, develops, and ultimately evaluates the performance of instructors through a process of inquiry that encourages their understanding and articulation of the rationale for their own practices proved invaluable. I took the opportunity to introduce Instructor $G$ to at least four different formats of a reflection instrument that I successfully use with students and faculty. My reflection instrument requires the user to identify three things learned; three things for which help is needed; three things s/he plans to do differently; and three things s/he plans to do the same. Further details of this are discussed in several of my books like Individualised Professional Development; Reflective Assessment and Service Learning; Differentiated Teaching That Works: An Educator's Guide; Teaching How To Think. etc.

Finally, technical assistance aimed at assisting instructors to improve by offering resources and information, supporting networking and change efforts formed part of my IPD. I advised on a variety of online courses offered by several universities on many platforms: Coursera, Canvas, EdX, FutureLearn, etc. Interestingly, the foregoing methods are in keeping with those described in (Wikipdeia, 2012).

\section{DISCUSSION AND CONCLUSION}

This present paper examined how instructors in HE experienced IPD. This paper defined IPD as professional development administered on an individual or one-on-one basis, where the specific idiosyncratic individual needs of the recipient are addressed. IPD was seen as particularly attractive to instructors because it provided them with learning opportunities that directly related to their personal needs.

We noted that a range of strategies were used for IPD. Some of the approaches used included case studies; consultations; coaching; communities of practice; lesson studies; mentoring; reflective supervision; and technical assistance. Instructors shared their personal lived experiences that give us some insights into what other researchers and practitioners may find useful in their ongoing practice.

The results of this present study allow us to summarise some advantages of IPD as being able to differentiate to meet individual needs and personal interests; convenient to meet diverse personal needs in a consistently changing environment; allows individuals to keep abreast with current trends and develop life skills; and maximises exposure to current issues and ideas in education. IPD also provides opportunities to exchange ideas and experiences; optimises knowledge gain about research findings of personal interests; provides an avenue for renewal of state licenses for personal academic practice; facilitates flexibility in scheduling; and builds local capacity for improved instruction and leadership. Additionally, IPD creates more fun in learning for both students and teachers; produces less discipline problems because of active engagement in learning and learners having a greater stake in the outcome of what is learned. Finally, IPD provides individuals with the ability to learn life skills that will be used repeatedly; and increases capacity for upward mobility. By the same token, the results of this present study allow us to summarise some disadvantages of IPD as having the capacity to appear to be less orderly and less comfortable to an authoritarian-style teacher; be more time consuming; may appear to be more labour intensive, requiring patience and guidance by the instructor/facilitator; and usually there is often no single "right" answer.

This results of this study have far reaching implications for educators and practitioners in the way they provide IPD to their charges. Issues arising from this study that may be explored at a future time include: How can IPD help faculty to improve their teaching and learning experiences?; How can faculty in HE increase the gains from IPD?; What specific strategies in IPD could benefit faculty in their personal lives?

\section{REFERENCES}

[1] R.C.Wei, L. Darling-Hammond, A, Andree, N, Richardson, S. Orphanos, Professional Learning in the Learning Profession: A Status Report on Teacher Development in the United States and Abroad, National Staff Development Council, 2009.

[2] The Center for Technology in Learning, SRI International (2009). Systemic vs. one-time teacher professional development: what does research say? Research 15. http://ti-researchlibrary.com/Lists/TI\%20Education\%20Technology\%20 \%20Research\%20Library/Attachments/192/CL9847\%20Research_Note 15\%20PD.pdf

[3] F. von Glasersfeld, F., Radical Constructivism:A way of Knowing and Leaning. London, RoutledgeFalmer,1995. https://doi.org/10.4324/9780203454220

[4] D.K. Cohen \& D.L. Ball, Instruction and innovation: Reconsidering the story. Working paper, Consortium for Policy Research in Education, Study of Instructional Improvement. Ann Arbor, MI: University of Michigan, 2000.

[5] D.H. Jonassen, Thinking Technology: toward a constructivist design model. Educational Technology, April, 1994, pp.34-37.

[6] Mississippi Department of Education, The Teacher's Academy. http://www.theteachersacademy.com/find-your-state/south/mississippi/? url=find-your-state\%2Fsouth\%2Fmississippi\%2F, 2016.

[7] S. Sawchuk, Professional Development for Teachers at Crossroads. Education Week, November 10, 2010.

[8] P. Honebein, "Seven goals for the design of Constructivist learning environments" in B. Wilson, Constructivist learning environments, Englewood Cliffs, NJ: Educational Technology Publications ISTE (2006), 1996, pp.17-24.

[9] Professional Development. Retrieved Wikipedia October 20, 2016 from http://en.wikipedia.org/wiki/Professional_development,2012.

[10] B.McDonald, Individualised Professional Development. OmniScriptum GmbH \& Co. KG., Saarbrucken, Germany, 2013.

[11] B. McDonald, Reflective Assessment and Service Learning. OmniScriptum GmbH \& Co. KG, Saarbrucken, Germany, 2012.

[12] B. McDonald, Differentiated Teaching That Works: An Educator's Guide. OmniScriptum GmbH \& Co. KG, Saarbrucken, Germany,2016. 